Parenteral plant sterols accumulate in the liver reflecting their increased serum levels and portal inflammation in children with intestinal failure

Hukkinen, M

2017-08

Hukkinen, M , Mutanen , A , Nissinen, M , Merras-Salmio , L , Gylling , H \& Pakarinen , M P 2017 , ' Parenteral plant sterols accumulate in the liver reflecting their increased serum levels and portal inflammation in children with intestinal failure ' , Journal of Parenteral and Enteral Nutrition, vol. 41 , no. 6 , pp. 1014-1022 .

https://doi.org/10.1177/0148607116637855, https://doi.org/10.1177/0148607116637855

http://hdl.handle.net/10138/298083

https://doi.org/10.1177/0148607116637855

publishedVersion

Downloaded from Helda, University of Helsinki institutional repository.

This is an electronic reprint of the original article.

This reprint may differ from the original in pagination and typographic detail.

Please cite the original version. 


\title{
Parenteral Plant Sterols Accumulate in the Liver Reflecting Their Increased Serum Levels and Portal Inflammation in Children With Intestinal Failure
}

Journal of Parenteral and Enteral Nutrition

Volume 41 Number 6

August 2017 1014-1022

(C) 2016 American Society

for Parenteral and Enteral Nutrition DOI: $10.1177 / 0148607116637855$

journals.sagepub.com/home/pen

\author{
Maria Hukkinen, MD, PhD ${ }^{1,2}$; Annika Mutanen, MD, PhD ${ }^{1,2}$; \\ Markku Nissinen, MD, $\mathrm{PhD}^{3}$; Laura Merras-Salmio, $\mathrm{MD}, \mathrm{PhD}^{1,4}$; \\ Helena Gylling, MD, PhD ${ }^{5}$; and Mikko P. Pakarinen, MD, PhD ${ }^{1,2}$
}

\begin{abstract}
Background: Parenteral plant sterols (PSs) are considered hepatotoxic; however, liver PSs and their associations with liver injury in patients with intestinal failure (IF) have not been reported. Materials and Methods: We analyzed liver and serum PS (avenasterol, campesterol, sitosterol, and stigmasterol) concentrations and ratios to cholesterol and their associations with biochemical and histologic liver damage in children with IF during $(\mathrm{n}=7)$ parenteral nutrition $(\mathrm{PN})$ and after weaning off it $(\mathrm{n}=9)$, including vegetable oil-based lipid emulsions. Results: Liver avenasterol, sitosterol, and total PS concentrations and cholesterol ratios were 2.4-fold to 5.6-fold higher in PN-dependent patients $(P<.05)$. Parenteral PS delivery reflected liver avenasterol and sitosterol ratios to cholesterol $(r=0.83-$ $0.89, P=.02-.04)$, while serum and liver total PS levels were positively interrelated $(r=0.98, P<.01)$. Any liver histopathology was equally common while portal inflammation more frequent (57 vs $0 \%, P=.02)$ in PN-dependent patients. All liver PS fractions correlated positively with histologic portal inflammation $(r=0.53-0.66, P<.05)$, and their total concentration was significantly $(P=.01)$ higher among patients with versus without portal inflammation. In PN-dependent patients, liver fibrosis and any histopathology correlated with liver campesterol and stigmasterol levels $(r=0.79-0.87, P \leq .03)$. Conclusion: Among children with IF, parenteral PSs accumulate in the liver, reflect their increased serum levels, and relate with biochemical liver injury, portal inflammation, and liver fibrosis, thus supporting their role in promoting liver damage. (JPEN J Parenter Enteral Nutr. 2017;41:1014-1022)
\end{abstract}

\section{Keywords}

intestinal failure-associated liver disease; parenteral nutrition; phytosterols; lipid emulsions; short bowel syndrome

\section{Clinical Relevancy Statement}

Although parenteral plant sterols are assumed to accumulate in the liver, current knowledge on their distribution in the human body is based on serum plant sterol measurements. This is the first study demonstrating that liver plant sterol concentrations are elevated during parenteral nutrition and that their increased levels relate with biochemical and histological liver injury in children with intestinal failure.

\section{Introduction}

Parenteral nutrition $(\mathrm{PN})$ is a life-saving therapy for patients with intestinal failure (IF). PN dependence, however, predisposes to IF-associated liver disease (IFALD), the most significant and lifethreatening complication of IF. $^{1-3}$ IFALD is the most common indication for intestinal transplantation in children, among whom young gestational age, extensive bowel resection, and lack of enteral nutrition further increase the risk of liver damage. ${ }^{1,4}$ Early histopathologic changes characteristic to IFALD include portal inflammation (PI) and cholestasis, while fibrosis and steatosis develop with time and persist after weaning off $\mathrm{PN}$. $^{2,5}$

Vegetable oil-based PN solutions contain variable amounts of plant sterols (PSs), equivalent to cholesterol in mammals, which cannot be synthesized in the human body. ${ }^{6,7}$ Current research evidence suggests that PSs significantly contribute to IFALD

From ${ }^{1}$ Pediatric Liver and Gut Research Group, Children's Hospital, Helsinki University Hospital, Helsinki, Finland; ${ }^{2}$ Section of Pediatric Surgery, Children's Hospital, Helsinki University Hospital and University of Helsinki, Helsinki, Finland; ${ }^{3}$ Abdominal Center, Helsinki University Hospital and University of Helsinki, Helsinki, Finland; ${ }^{4}$ Section of Pediatric Gastroenterology, Children's Hospital, Helsinki University Central Hospital and University of Helsinki, Helsinki, Finland; and ${ }^{5}$ Internal Medicine, Helsinki University Central Hospital and University of Helsinki, Helsinki, Finland.

Financial disclosure: This study was supported by grants from the Finnish Pediatric Research Foundation, the Sigrid Jusélius Foundation, and the Helsinki University Central Hospital research funds.

Conflicts of interest: None declared.

Received for publication December 5, 2015; accepted for publication February 7, 2016.

This article originally appeared online on March 9, 2016.

\section{Corresponding Author:}

Mikko P. Pakarinen, MD, PhD, Section of Pediatric Surgery, Pediatric Liver and Gut Research Group, Children's Hospital, Helsinki University Central Hospital, Stenbackinkatu 11, PO Box 281, 00029 HUS, Helsinki, Finland. Email: mikko.pakarinen@hus.fi 
development. ${ }^{4,6-10}$ In healthy individuals, the small amount of absorbed dietary PS is excreted into bile, and serum PS levels remain low. ${ }^{6,7}$ As liver capacity to metabolize PS is limited, ${ }^{11}$ intravenously administered soy oil-based and olive oil-based PN emulsions substantially increase serum PS concentrations. Elevated serum PS levels during PN are associated with biochemical cholestasis, increased plasma liver enzyme levels, and IFALD-related liver histopathology, whereas reducing PN lipid dose decreases serum PS levels and improves liver dysfunction. ${ }^{6-9,12-15}$ The finding that substituting soy oil-based PN with fish oil-based emulsion devoid of PS can reverse liver injury further supports the role of PS in IFALD development. ${ }^{1,16}$ In animal models, PS levels increase rapidly following PN initiation, not only in serum, but also in the liver. ${ }^{4,7,10,17}$ The ensuing cholestasis and hepatocyte damage have been demonstrated in vitro to be mediated by PSs, which inhibit the nuclear farnesoid $\mathrm{X}$ receptor (FXR), a bile acid sensor and a key regulator of bile acid and sterol homeostasis in the liver. ${ }^{4,10}$ Importantly, PSs may also promote hepatic inflammation by suppressing FXR and directly activating liver macrophages. ${ }^{4}$ Parenteral PSs are assumed to act in the human body similarly as in animal models; however, no direct evidence on their hepatic accumulation and associated effects exists in IF patients. In this study, we aimed to find out whether PSs accumulate in the liver during PN, whether serum and liver PS levels are correlated, and whether liver PSs associate with liver histopathology. To meet these aims, we compared serum and liver PS levels between patients currently receiving $\mathrm{PN}$ and those weaned off PN, analyzed their interrelations, and studied their associations with PN characteristics, biochemical markers of liver function, and liver histopathology in children with IF.

\section{Methods}

\section{Patients and Study Design}

For this study, children with IF managed by our intestinal rehabilitation program who were receiving $\mathrm{PN}(\mathrm{n}=7)$ or were weaned off PN ( $n=9)$ were enrolled during 2011-2015..$^{18}$ IF was defined as $\mathrm{PN}$ requirement for $>3$ consecutive months or small bowel resection $>50 \%$ of age-adjusted bowel length., ${ }^{3,19}$ Routine liver biopsies were taken in PN-dependent patients if PN duration exceeded 1 month or progressive liver dysfunction was observed. Follow-up biopsies after weaning off $\mathrm{PN}$ were scheduled if liver histopathology was present in a previous biopsy or if biochemical liver function parameters deteriorated over time. ${ }^{20}$ Patients underwent liver biopsy and serum sampling after an overnight fast during the same day. Core needle liver biopsies were obtained during intestinal surgery or under ultrasound guidance during general anesthesia for gastroscopy. ${ }^{5}$ As serum PS concentrations are known to remain elevated for some weeks after PN cessation, ${ }^{8}$ patients weaned from PN were included if they had not received parenteral support for at least 3 months prior the study.

Medical records were reviewed for baseline diagnoses, previous surgical procedures, and intestinal anatomy. Length of the remaining small bowel was expressed as a percentage of the age-adjusted reference values. ${ }^{19}$ Growth parameters and PN duration were recorded. Detailed PN data were collected for those receiving PN at the time of biopsy, including the number of weekly PN infusions as well as intake of PN energy ( $\mathrm{kcal} / \mathrm{kg} / \mathrm{d}$ and as proportion to total energy intake), glucose $(\mathrm{g} / \mathrm{kg} / \mathrm{d})$, fat $(\mathrm{g} / \mathrm{kg} / \mathrm{d}$ and as proportion of PN energy), cholesterol $(\mu \mathrm{g} / \mathrm{kg} / \mathrm{d})$, and total PSs $(\mu \mathrm{g} / \mathrm{kg} / \mathrm{d}){ }^{15,21}$ Routine biochemical liver tests, including alanine aminotransferase, aspartate aminotransferase, glutamyl transferase (GT), bilirubin, bile acids, albumin, and prothrombin time, as well as serum and lipoprotein lipids, were analyzed by our hospital laboratory.

\section{Liver Biopsies}

The liver biopsy material was divided between histologic stainings and PS analysis. Histologic specimens were fixed in formalin, embedded in paraffin, sliced, and stained with hematoxylin and eosin. Additional stainings included reticulin, periodic acid-Schiff, copper, iron, and immunostaining for a biliary epithelial marker cytokeratin $7 .^{5}$ Liver histology was evaluated by experienced pediatric pathologists blinded from other study variables. Biopsy specimens were considered representative, as they contained a median of 11 portal tracts (interquartile range [IQR], 10-15). Fibrosis was graded according to Metavir stage as follows: no fibrosis (F0), portal fibrosis without septa (F1), portal fibrosis and few septa (F2), numerous septa without cirrhosis (F3), or cirrhosis (F4). ${ }^{22}$ PI was defined as abnormal inflammatory cell infiltration in portal areas. Cholestasis was graded as absent or present, and steatosis was present if the proportion of hepatocytes with fat deposits exceeded $10 \%{ }^{5}$

\section{PS Analyses}

Serum and liver cholesterol and PS fractions (campesterol, sitosterol, stigmasterol, and avenasterol) were measured with gas-liquid chromatography on a 50-m-long SE-30 nonpolar capillary column (Ultra 2 Column; Agilent Technologies, Palo Alto, CA), with $5 \alpha$-cholestane as internal standard. ${ }^{23}$ Serum PS concentrations were expressed as $\mu \mathrm{g} / \mathrm{dL}$ and as a ratio to the cholesterol concentration of the same gas-liquid chromatography run $(100 \times \mu \mathrm{g} / \mathrm{mg}$ of cholesterol, called ratios in the text). The liver biopsy material used for PS analysis, weighing a median of $4.3 \mathrm{mg}$ (IQR, 2.3-6.1 mg), was snap frozen and stored at $-20^{\circ} \mathrm{C}$ until analyzed. The results were expressed as $\mu \mathrm{g} / 100 \mathrm{~g}$ of liver tissue and as ratio to the cholesterol concentration of liver tissue of the same gas-liquid chromatography run $(100 \times \mu \mathrm{g} / \mathrm{mg}$ of cholesterol, called ratios in the text). Serum PS data were missing for 1 patient.

\section{Statistical Analyses}

Data are expressed as medians (IQRs) or as frequencies. MannWhitney $U$ test was used to compare continuous variables and 
Fisher exact test to compare frequencies between groups. Spearman rank correlation was used to examine associations between variables. Simple linear regression was used to analyze the value of serum PSs to predict liver PS concentrations. All analyses were carried out with SPSS 22 (SPSS Inc, Chicago, IL).

\section{Ethic}

This study was approved by the Helsinki University Central Hospital ethics committee (2/13/03/03/2010) and institutional review board $(57 / 2010,12 / 2013)$. Written informed consent was received from all patients or their caregivers before any procedures.

\section{Results}

\section{Patient Characteristics}

Of the 15 patients ( $53 \%$ males, $\mathrm{n}=8), 1$ had chronic intestinal pseudo-obstruction, while 14 had short bowel syndrome (SBS) due to necrotizing enterocolitis $(n=6)$, small bowel atresia $(n=$ $4)$, midgut volvulus $(\mathrm{n}=3)$, or intestinal resection for Hirschsprung's disease extending to duodenojejunal flexure $(\mathrm{n}=$ 1). Compared with age-adjusted reference values, ${ }^{19}$ patients had $25 \%(17 \%-31 \%)$ of small bowel and $75 \%(40 \%-100 \%)$ of colon remaining (no difference between patients receiving $\mathrm{PN}$ and not). The ileum was missing in 6 patients and the ileocecal valve in 7.

Growth data, liver biochemistry, and liver histology are shown in Table 1. Higher plasma GT was observed in patients receiving PN versus not. One-third to two-thirds of PN-dependent patients had increased transaminases, GT, and bile acids, while all patients had normal total bilirubin. Histological fibrosis (F1, F2) and any liver histopathology (steatosis, fibrosis, cholestasis, or PI) were equally common between subgroups, while PI was more frequent in patients receiving $\mathrm{PN}$ versus not.

\section{Nutrition}

At time of liver biopsy, 9 patients had weaned off PN 67 (9.699) months earlier after receiving $\mathrm{PN}$ for 11 (4.9-14) months (Table 2). The remaining subjects $(\mathrm{n}=7)$ had been receiving PN for 11 (5.5-16) months, currently receiving 7 (6.5-7) PN infusions/week and $50 \%(33 \%-83 \%)$ of total daily calories parenterally, $13 \%(13 \%-21 \%)$ of which composed of fat. A combination of olive oil, soy oil, medium-chained triglycerides, and fish oil (SMOFlipid; Fresenius Kabi) was used in 1 patient; soy- and olive oil (20\%/80\%)-based lipid emulsion (Clinoleic, Baxter) in 5 ; and a combination of soy, olive $(5 \% / 22 \%$; Clinoleic), and fish oil (73\%; Omegaven, Fresenius Kabi) in 1.

\section{Serum Cholesterol and PSS}

Serum cholesterol was comparable between subgroups (Table 3). Concentrations and ratios of sitosterol, stigmasterol, and total PS
Table 1. Age, Growth, Liver Biochemistry, Serum Lipids, and Liver Histology in Patients With Intestinal Failure Who Were Receiving PN and Weaned Off PN. ${ }^{\mathrm{a}}$

\begin{tabular}{|c|c|c|}
\hline Variable & $\begin{array}{l}\text { Patients } \\
\text { Receiving PN } \\
(\mathrm{n}=7)\end{array}$ & $\begin{array}{l}\text { Patients Weaned } \\
\text { Off PN }(n=9)\end{array}$ \\
\hline Age, y & $1.7(0.83,5.55)$ & $8.0(1.2,10.9)$ \\
\hline Height for age, SD & $-2.2(-2.5,-0.6)$ & $-1.7(-2.4,-0.2)$ \\
\hline $\begin{array}{l}\text { Weight for height, } \\
\text { percentiles }\end{array}$ & $-5(-9,-4)$ & $-6(-9,-3)$ \\
\hline $\mathrm{ALT}, \mathrm{IU} / \mathrm{L}$ & $34(24,71)$ & $30(21,34)$ \\
\hline Off reference limits & $2(29)$ & $2(22)$ \\
\hline $\mathrm{AST}, \mathrm{IU} / \mathrm{L}$ & $41(36,61)$ & $35(32,39)$ \\
\hline Off reference limits & $3(43)$ & 0 \\
\hline GT, IU/L & $29(20,56)$ & $15(11,16)^{b}$ \\
\hline Off reference limits & $2(29)$ & 0 \\
\hline Total bilirubin, $\mu \mathrm{mol} / \mathrm{L}$ & $3(2.5,4)$ & $6(5,12)^{\mathrm{c}}$ \\
\hline Off reference limits & 0 & 0 \\
\hline Bile acids, $\mu \mathrm{mol} / \mathrm{L}$ & $6.5(5.0,13)$ & $13(8.4,18)^{\mathrm{d}}$ \\
\hline Off reference limits & $4(57)$ & $2(67)^{d}$ \\
\hline Albumin, $\mathrm{g} / \mathrm{L}$ & $33(28,37)$ & $41(40,42)$ \\
\hline Off reference limits & $6(86)$ & $1(11)^{\mathrm{c}}$ \\
\hline Prothrombin time & $73(63,79)$ & $83(58,111)$ \\
\hline Off reference limits & $3(43)$ & $3(33)$ \\
\hline Cholesterol, mmol/L & $2.9(2.4,3.7)$ & $3.3(2.4,3.8)$ \\
\hline LDL & $1.5(1.2,1.6)$ & $1.3(1.0,1.7)$ \\
\hline HDL & $1.0(0.8,1.3)$ & $1.1(0.9,1.6)$ \\
\hline Triglycerides & $0.76(0.54,1.1)$ & $0.91(0.52,1.2)$ \\
\hline \multicolumn{3}{|l|}{ Liver histology } \\
\hline Cholestasis & $1(14)$ & 0 \\
\hline Portal inflammation & $4(57)$ & $0^{\mathrm{c}}$ \\
\hline Steatosis & $3(43)$ & $4(44)$ \\
\hline Fibrosis & $5(71)$ & $5(56)$ \\
\hline Any histopathology & $5(71)$ & $7(78)$ \\
\hline
\end{tabular}

ALT, alanine aminotransferase; AST, aspartate aminotransferase; GT, gamma-glutamyl transferase; HDL, high-density lipoprotein; LDL, lowdensity lipoprotein; PN, parenteral nutrition.

${ }^{a}$ Data are presented as medians (interquartile range) or $\mathrm{n}(\%) . P$ values for the differences between subgroups were calculated by MannWhitney $U$ test for continuous variables and Fisher exact test for frequencies.

${ }^{\mathrm{b}} P \leq .01$.

${ }^{\mathrm{c}} P \leq .05$.

${ }^{\mathrm{d}}$ Measured for 3 patients weaned off PN.

as well as avenasterol ratios were higher in patients receiving PN than not (Table 3, Figure 1A). Sitosterol constituted 78\% (71\%$79 \%$ ) of serum total PS in PN-dependent patients, while campesterol was the most abundant individual serum PS in patients weaned off PN, at 51\% (49\%-59\%) of total PS. Parenteral lipid energy percentage was related with serum sitosterol concentration and ratio, stigmasterol ratio, avenasterol ratio, and total PS concentration and ratio ( $r=0.81-0.84, P \leq .05$ for all). Daily fat intake $(\mathrm{g} / \mathrm{kg})$ and number of weekly PN infusions correlated with serum stigmasterol concentration and ratio $(r=0.83-0.94$, 
Table 2. Characteristics of PN Preceding Liver Biopsy.

\begin{tabular}{lc}
\hline & $\begin{array}{c}\text { Patients } \\
\text { Receiving PN } \\
(\mathrm{n}=7)\end{array}$ \\
Characteristic & \\
\hline PN lipid emulsion, $\mathrm{n}$ & 5 \\
Clinoleic (soy and olive oil) & 1 \\
SMOF (soy, olive, fish oil, and medium- & \\
chained triglycerides) & 1 \\
Clinoleic + Omegaven (soy, olive, and & \\
fish oil) & \\
PN, median (interquartile range) & $11(5.5-16)$ \\
Duration, mo & $7(6.5-7)$ \\
Infusions $/ \mathrm{wk}$ & $617(482-789)$ \\
Total calories $/ \mathrm{d}$ & $51(37-65)$ \\
Calories $/ \mathrm{kg} / \mathrm{d}$ & $50(33-83)$ \\
Proportion of total daily calories & $8.1(7.8-12.2)$ \\
Glucose, $\mathrm{g} / \mathrm{kg} / \mathrm{d}$ & $1.1(0.47-1.7)$ \\
Fat, $\mathrm{g} / \mathrm{kg} / \mathrm{d}{ }^{\mathrm{a}}$ & \\
Cholesterol, $\mu \mathrm{g} / \mathrm{kg} / \mathrm{d}^{\mathrm{a}}$ & $906(805-959)$ \\
Plant sterols, $\mu \mathrm{g} / \mathrm{kg} / \mathrm{d}^{\mathrm{a}}$ & $1522(464-2287)$ \\
\hline
\end{tabular}

$\mathrm{PN}$, parenteral nutrition.

${ }^{\mathrm{a}}$ Detailed parenteral lipid dosage was not available for 1 patient $(\mathrm{n}=6)$.

$P<.01-.04$ for all). Daily PS intake $(\mu \mathrm{g} / \mathrm{kg})$ correlated with serum sitosterol concentration and ratio $(r=0.83, P=.04$ for both), stigmasterol concentration $(r=0.89, P=.02)$, and total PS concentration and ratio ( $r=0.83, P=.04$ for both).

\section{Liver Cholesterol and PSs}

Liver cholesterol concentrations were similar, while concentrations and ratios of sitosterol, avenasterol, and total PS were higher in patients receiving PN versus not (Table 3, Figure 1B). In PN-dependent patients, sitosterol was the most abundant individual liver PS, composing 55\% (52\%-59\%) of total PS, whereas in patients off PN, campesterol constituted 35\% (32\%-46\%) and sitosterol 28\% (25\%-29\%) of liver PS. Time having been off PN correlated negatively while parenteral lipid energy percentage correlated positively with sitosterol concentration $(r=-0.58, P=.02$; $r=0.76, P=.05)$ and ratio $(r=-0.74, P<.01 ; r=0.81, P=.05)$, avenasterol ratio $(r=-0.54, P=.03 ; r=0.81, P=.05)$, and total liver PS ratio ( $r=-0.70, P<.01 ; r=0.84, P=.04$, respectively). Among PN-dependent patients, number of weekly PN infusions correlated positively with sitosterol and total liver PS concentrations ( $r=0.76, P=.05$ for both) and PS intake with liver ratios of sitosterol and avenasterol $(r=0.83, P=.04 ; r=0.87, P=.02)$.

\section{Interrelations Between Serum and Liver PSS}

The linear regression model suggested that total serum PS was a strong predictor of liver PS levels among all patients $(r=$ $0.83, P<.01$ for absolute concentrations; $r=0.98, P<.01$ for ratios to cholesterol; Figure $1 \mathrm{C}$ and $1 \mathrm{D})$. Of different PS
Table 3. Serum and Liver Plant Sterol Concentrations and Ratios to Cholesterol. ${ }^{\mathrm{a}}$

\begin{tabular}{|c|c|c|}
\hline Concentration: Ratio & $\begin{array}{c}\text { Patients Receiving } \\
\text { PN }\end{array}$ & $\begin{array}{c}\text { Patients Weaned } \\
\text { Off PN }\end{array}$ \\
\hline Serum, $\mathrm{n}$ & 6 & 9 \\
\hline Cholesterol, mg/dL & $110(89-137)$ & $122(90-140)$ \\
\hline Campesterol, $\mu \mathrm{g} / \mathrm{dL}$ & $351(176-458)$ & $254(157-418)$ \\
\hline $\begin{array}{c}100 \times \mu \mathrm{g} / \mathrm{mg} \text { of } \\
\text { cholesterol }\end{array}$ & $256(180-514)$ & $181(129-343)$ \\
\hline Stigmasterol, $\mu \mathrm{g} / \mathrm{dL}$ & $78(33-134)$ & $18(12-22)^{\mathrm{b}}$ \\
\hline $\begin{array}{c}100 \times \mu \mathrm{g} / \mathrm{mg} \text { of } \\
\text { cholesterol }\end{array}$ & $65(40-128)$ & $14(13-17)^{\mathrm{b}}$ \\
\hline Sitosterol, $\mu \mathrm{g} / \mathrm{dL}$ & $1713(593-2769)$ & $186(85-191)^{\mathrm{b}}$ \\
\hline $\begin{array}{c}100 \times \mu \mathrm{g} / \mathrm{mg} \text { of } \\
\text { cholesterol }\end{array}$ & $1364(609-3119)$ & $114(85-157)^{\mathrm{b}}$ \\
\hline Avenasterol, $\mu \mathrm{g} / \mathrm{dL}$ & $92(49-141)$ & $41(38-67)$ \\
\hline $\begin{array}{c}100 \times \mu \mathrm{g} / \mathrm{mg} \text { of } \\
\text { cholesterol }\end{array}$ & $66(53-156)$ & $40(36-42)^{\mathrm{c}}$ \\
\hline $\begin{array}{l}\text { Total plant sterols, } \\
\mu \mathrm{g} / \mathrm{dL}\end{array}$ & $2193(837-3480)$ & $512(322-675)^{\mathrm{c}}$ \\
\hline $\begin{array}{c}100 \times \mu \mathrm{g} / \mathrm{mg} \text { of } \\
\text { cholesterol }\end{array}$ & $1750(859-3920)$ & $340(279-554)^{\mathrm{b}}$ \\
\hline Liver, $\mathrm{n}$ & 7 & 9 \\
\hline Cholesterol, mg/100 g & $366(338-478)$ & $312(295-323)$ \\
\hline Campesterol, $\mu \mathrm{g} / 100 \mathrm{~g}$ & $1298(818-2423)$ & 1014 (591-1923) \\
\hline $\begin{array}{c}100 \times \mu \mathrm{g} / \mathrm{mg} \text { of } \\
\text { cholesterol }\end{array}$ & $355(261-572)$ & $234(209-442)$ \\
\hline Stigmasterol, $\mu \mathrm{g} / 100 \mathrm{~g}$ & $319(267-1434)$ & $385(240-429)$ \\
\hline $\begin{array}{c}100 \times \mu \mathrm{g} / \mathrm{mg} \text { of } \\
\text { cholesterol }\end{array}$ & $120(81-248)$ & $103(70-133)$ \\
\hline Sitosterol, $\mu \mathrm{g} / 100 \mathrm{~g}$ & $3933(2731-9186)$ & $754(515-1000)^{\mathrm{b}}$ \\
\hline $\begin{array}{c}100 \times \mu \mathrm{g} / \mathrm{mg} \text { of } \\
\text { cholesterol }\end{array}$ & $1100(733-2289)$ & $196(182-309)^{\mathrm{b}}$ \\
\hline Avenasterol, $\mu \mathrm{g} / 100 \mathrm{~g}$ & $2156(1089-3541)$ & $692(455-1000)^{\mathrm{c}}$ \\
\hline $\begin{array}{c}100 \times \mu \mathrm{g} / \mathrm{mg} \text { of } \\
\text { cholesterol }\end{array}$ & $575(390-676)$ & $222(144-247)^{\mathrm{c}}$ \\
\hline $\begin{array}{l}\text { Total plant sterols, } \\
\mu \mathrm{g} / 100 \mathrm{~g}\end{array}$ & $7134(4933-16,584)$ & $3000(2189-3943)^{c}$ \\
\hline $\begin{array}{c}100 \times \mu \mathrm{g} / \mathrm{mg} \text { of } \\
\text { cholesterol }\end{array}$ & $1996(1524-3926)$ & $708(672-1082)^{\mathrm{b}}$ \\
\hline
\end{tabular}

PN, parenteral nutrition.

${ }^{a}$ Cholesterol and plant sterol concentrations assessed with gas-liquid chromatography. Unless noted otherwise, data are presented as medians (interquartile range). $P$ values for the differences between subgroups were calculated by Mann-Whitney $U$ test.

${ }^{\mathrm{b}} P \leq .01$.

${ }^{\mathrm{c}} P \leq .05$.

fractions, serum/liver concentrations and ratios of sitosterol and avenasterol were positively interrelated in PN-dependent patients. In patients weaned off $\mathrm{PN}$, serum/liver ratios of campesterol were positively and ratios of stigmasterol negatively interrelated (Table 4).

\section{Serum and Liver PSs in Relation to Biochemical Liver Function}

Serum stigmasterol concentration and ratio correlated positively with GT $(r=0.61, P=.02 ; r=0.59, P=.02$, respectively), and sitosterol concentration with aspartate 

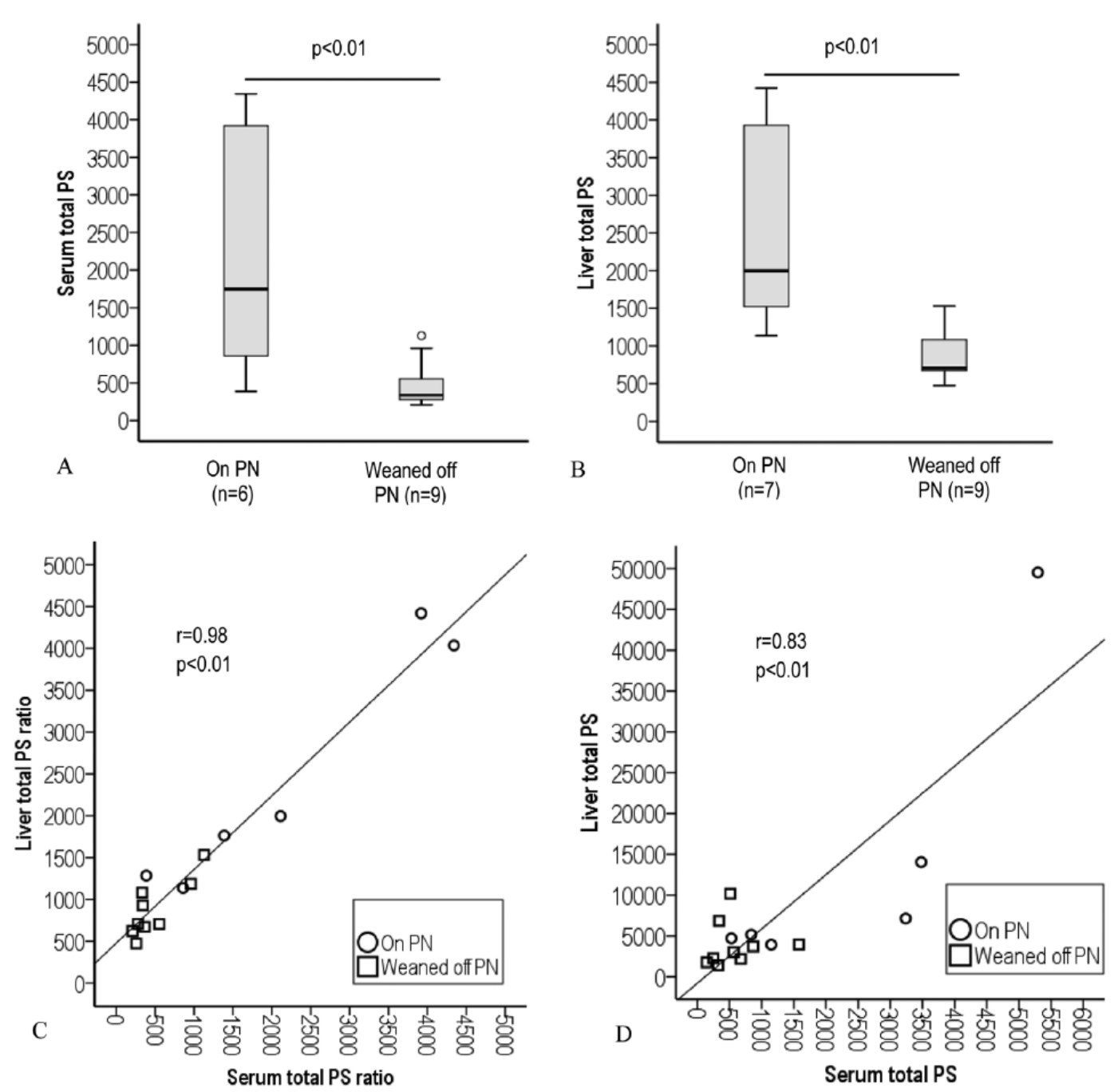

Figure 1. Subgroup comparison of total plant sterol (PS) ratios to cholesterol (100 $\times \mu \mathrm{g} / \mathrm{mg}$ of cholesterol) in (A) serum and (B) liver. The box plots display median, interquartile range, and range. The round dot represents a value larger than the upper quartile plus 1.5 times the interquartile range. $P$ values for the differences between subgroups were calculated by Mann-Whitney $U$ test. Regression plots between serum and liver total PS (C) ratios to cholesterol $(100 \times \mu \mathrm{g} / \mathrm{mg}$ of cholesterol) and (D) concentrations ( $\mu \mathrm{g} / 100 \mathrm{~g}$ of liver tissue). $\mathrm{PN}$, parenteral nutrition.

aminotransferase $(r=0.53, P=.04)$. Liver total PS ratio correlated positively with GT $(r=0.52, P=.04)$ and liver sitosterol ratio with GT $(r=0.63, P=.01)$ and albumin $(r=$ $-0.52, P=.04)$.

\section{Cholesterol and Liver Histology}

In all patients, serum cholesterol was inversely related with histologic steatosis $(r=-0.66, P<.01)$. Among PN-dependent patients, serum cholesterol correlated negatively with steatosis $(r=-0.83, P=.04)$ and parenteral cholesterol intake with fibrosis, steatosis, and any liver histopathology $(r=-0.83$,
$P=.04$ for all). Among patients weaned off PN, serum cholesterol correlated negatively with the presence of any liver histopathology $(r=-0.73, P=.03)$.

\section{Serum and Liver PSS in Relation to Liver Histology}

Histologic PI correlated positively with GT $(r=0.65, P<.01)$ and serum avenasterol concentration and ratio $(r=0.58, P=$ $.02 ; r=0.54, P=.04$, respectively). Liver concentrations of all PS fractions were significantly higher in patients with versus without PI (Figure 2). PI also correlated positively with all 
Table 4. Spearman Rank Correlations and Their $P$ Values Between Serum and Liver Plant Sterol Concentrations and Ratios to Cholesterol.

\begin{tabular}{|c|c|c|}
\hline \multirow[b]{2}{*}{ Plant Sterol } & \multicolumn{2}{|c|}{ Correlation ( $P$ Value) } \\
\hline & $\begin{array}{l}\text { PN-Dependent } \\
\text { Patients }(n=6)\end{array}$ & $\begin{array}{c}\text { Patients } \\
\text { Weaned Off } \\
\text { PN }(n=9)\end{array}$ \\
\hline Campesterol concentration & $0.54(.27)$ & $0.40(.29)$ \\
\hline Ratio to cholesterol & $0.71(.11)$ & $0.90(<.01)$ \\
\hline Stigmasterol concentration & $0.41(.43)$ & $-0.04(.91)$ \\
\hline Ratio to cholesterol & $0.49(.33)$ & $-0.87(<.01)$ \\
\hline Sitosterol concentration & $0.83(.04)$ & $0.24(.53)$ \\
\hline Ratio to cholesterol & $1.00(.01)$ & $0.38(.31)$ \\
\hline Avenasterol concentration & $0.83(.04)$ & $0.10(.80)$ \\
\hline Ratio to cholesterol & $0.83(.04)$ & $0.59(.10)$ \\
\hline Total plant sterol concentration & $0.83(.04)$ & $0.45(.22)$ \\
\hline Ratio to cholesterol & $0.87(.02)$ & $0.72(.03)$ \\
\hline
\end{tabular}

PN, parenteral nutrition.

liver PS concentrations and, apart from avenasterol, with their ratios to cholesterol: sitosterol ( $r=0.66, P<.01$ for both), avenasterol $(r=0.56, P=.02)$, stigmasterol $(r=0.53, P=.03$; $r=0.56, P=.02)$, campesterol $(r=0.53, P=.03 ; r=0.50, P<$ $.05)$, and liver total PS $(r=0.63, P<.01 ; r=0.66, P<.01$, respectively).

Among PN-dependent patients, liver campesterol concentration and ratio correlated positively with liver fibrosis $(r=$ $0.79, P=.03$ for both), PI ( $r=0.87, P=.01$ for both), and any histopathology ( $r=0.79, P=.03$ for both), whereas liver stigmasterol concentration and ratio correlated with fibrosis $(r=$ $0.79, P=.03$ for both $)$ and any liver histopathology $(r=0.79$, $P=.03$ for both). Table 5 displays individual liver biopsy findings in relation to liver PS content, parenteral PS delivery, and other patient characteristics among patients receiving PN. PI and fibrosis tended to occur in SBS children with the highest liver PS content, while the patient with chronic intestinal pseudo-obstruction with nearly an entire small intestine remaining had no evidence of liver histopathology, despite receiving the highest amounts of parenteral fat and energy.

\section{Discussion}

Although increasing evidence suggests that parenteral PSs are hepatotoxic, knowledge on their tissue distribution and metabolic effects is mainly based on animal models and remains largely unexplored in humans. ${ }^{4,7,10}$ This is the first study demonstrating that liver PS levels are markedly higher during PN than after weaning off PN and associate closely with parenteral delivery of vegetable oil-based lipid emulsions, suggesting that parenteral PSs accumulate in the liver during PN delivery in patients with IF. Serum PS levels were highly predictive of liver PS load. In patients receiving lipid emulsions with low stigmasterol and campesterol contents, ${ }^{21}$ parenteral PS intake also reflected liver sitosterol and avenasterol ratios to cholesterol. Serum and liver PS levels correlated with plasma GT, and all liver PS fractions associated with histologic PI, although none of the patients had biochemical cholestasis.

Hepatic accumulation of PSs during PN is thought to result from both their excess parenteral administration as well as their ability to suppress canalicular sterol transporters through inhibition of FXR. ${ }^{4,7,10}$ Accordingly, we found the highest liver concentrations for sitosterol, composing $70 \%-90 \%$ of total PSs in commercial parenteral vegetable oil lipid solutions. ${ }^{21,24}$ Compared with soy oil--based PN, the mixture of $80 \%$ olive oil and $20 \%$ soy oil has a similar sitosterol content while remarkably lower campesterol and stigmasterol contents. ${ }^{21,24}$ Sitosterol is secreted to bile more effectively than other PS fractions, ${ }^{11}$ possibly contributing to the decline of liver and serum PS levels after PN cessation in our patients. Indeed, sitosterol composed up to $90 \%$ of total PS intake in our patients, ${ }^{21,24}$ yet it made up $55 \%$ and $25 \%$ of total liver PS in patients receiving and weaned off $\mathrm{PN}$, respectively. Liver stigmasterol and campesterol concentrations, instead, did not differ in relation to PN status, and serum and liver stigmasterol were negatively correlated, suggesting that these PS fractions are probably excreted at a slower rate. ${ }^{11}$ The finding that transition from soy oil-based to olive oil-based PN may improve IFALD $^{14,15,25}$ may in part be explained by the different PS compositions of these solutions.

Delivery of fish oil-based PN associates with reversal of IFALD. ${ }^{1,16}$ Although this has been proposed to be mediated by its fatty acid composition and antioxidative characteristics, ${ }^{26}$ another possible explanation is the absence of PS in fish oil, supported by studies showing that adding stigmasterol to fish oil and administrating fish oil with soy oil can result in similar serum PS levels and hepatotoxicity than soy oil alone. , $^{4,13,16,27}$ Another potential benefit of fish oil is its higher cholesterol content versus soy and olive oil. ${ }^{21}$ Children receiving PN frequently present with abnormally low serum cholesterol, which, however, is essential for normal growth and development. ${ }^{15,28}$ PSs derived from PN are able to displace cell membrane cholesterol, which may decrease tissue elasticity and contribute to hepatocyte damage. ${ }^{7,29}$ Indeed, we found low cholesterol intake and low serum cholesterol to relate with PN duration as well as with liver fibrosis and steatosis. As serum and liver sterol proportions are distorted during PN, with high PS and low cholesterol levels reflecting the lipid profile of PN solutions, the ratio of each PS fraction to cholesterol probably mirrors the metabolic effects of PS better than their absolute concentrations.

Serum PS concentrations paralleled liver PS, and both reflected parenteral PS intake in piglets after only 2 weeks receiving PN. ${ }^{10}$ Accordingly, in addition to the observed correlation between PS intake and accumulation, we found serum total PS determination to be a useful method to estimate liver PS load, as these parameters were closely interrelated. No human data exist on the rate of hepatic PS accumulation after 

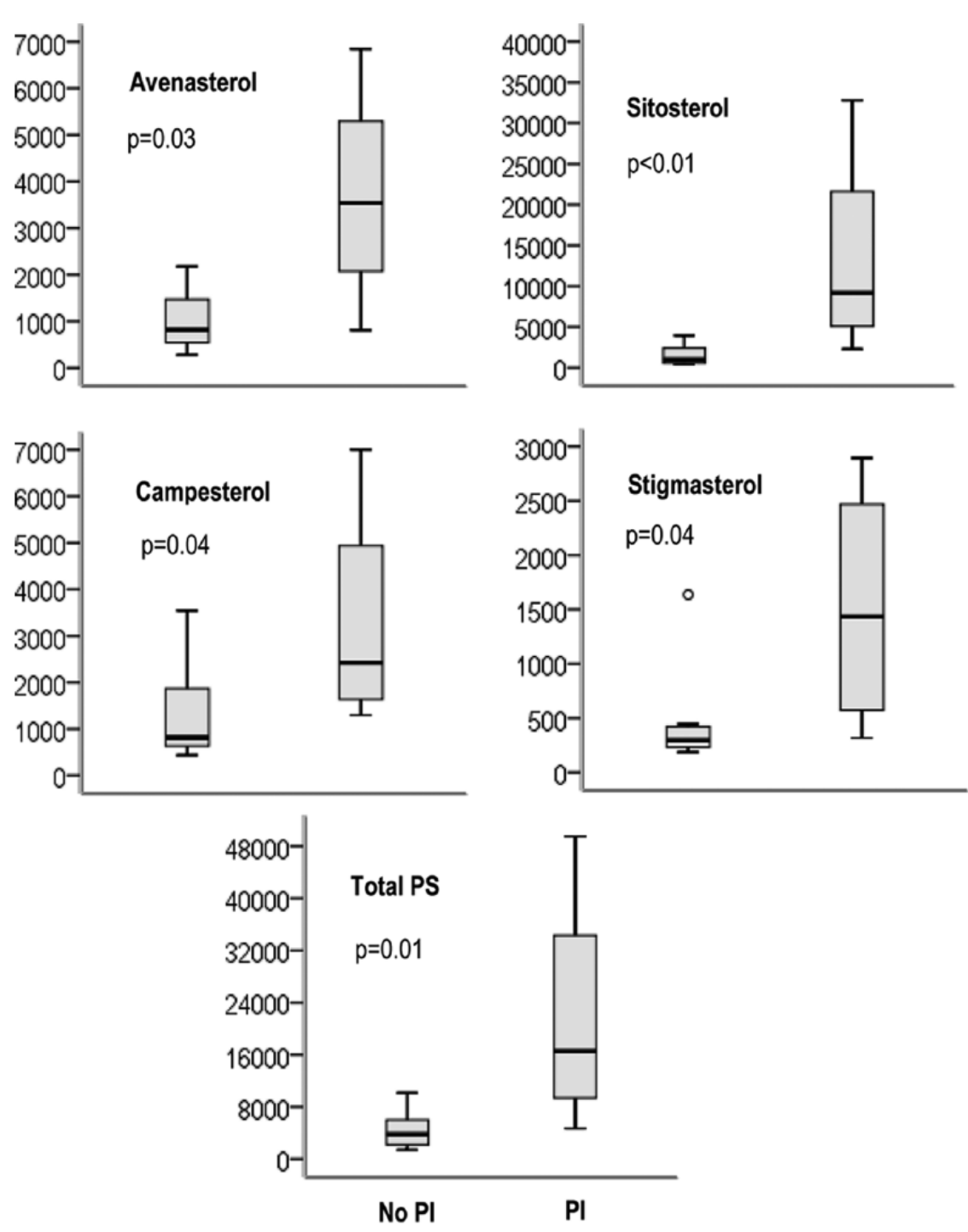

Figure 2. Comparisons of liver plant sterol (PS) concentrations ( $\mu \mathrm{g} / 100 \mathrm{~g}$ of liver tissue) between patients with $(\mathrm{n}=4)$ and without $(\mathrm{n}=12)$ histologic portal inflammation (PI). Box plots display median, upper and lower interquartile range, and range. The round dot represents a value larger than the upper quartile plus 1.5 times the interquartile range. $P$ values for the differences between subgroups were calculated by Mann-Whitney $U$ test.

initiation of PN. However, if this occurs as rapidly as suggested by animal studies, it could explain why PN-related cholestasis occasionally manifests after few weeks of PN. ${ }^{2,30}$ Apart from stigmasterol and campesterol, liver PS levels were lower after weaning off versus during PN, suggesting that accumulated PSs are eliminated after PN cessation. Moreover, serum PS levels of patients weaned off PN were similar to those previously reported among healthy children. ${ }^{8,12}$ Advanced liver damage could relate with protracted PS secretion ${ }^{9}$; however, advanced fibrosis or PI was not observed in any patient weaned off PN, although as many as $78 \%$ presented with IFALDrelated liver histology. Liver steatosis and fibrosis are known to persist after PN cessation, ${ }^{5}$ and our results suggest that this occurs regardless of dissolution of liver PS.

Experimental studies have demonstrated that sitosterol, stigmasterol, and campesterol downregulate FXR and decrease transcription of its target genes, ${ }^{4,10,31}$ which are involved in synthesis, uptake, and excretion of bile acids as well as excretion of sterols and phospholipids. Antagonism of FXR may promote cholestasis through all these mechanisms. ${ }^{4,10}$ In line with earlier studies, ${ }^{6-9,12-15}$ we found serum and liver PSs to correlate with GT, a sensitive marker of cholestasis and biliary injury. ${ }^{32}$ In PN-dependent patients, liver campesterol and stigmasterol also correlated with liver fibrosis. Furthermore, PS 
Table 5. IF Etiology, Age at Liver Biopsy, Characteristics of PN Preceding Liver Biopsy, Liver Total PSs, and Liver Biopsy Findings Presented Individually for PN-Dependent Patients $(n=7)$.

\begin{tabular}{|c|c|c|c|c|c|c|c|c|c|c|c|c|}
\hline \multirow[b]{2}{*}{ Patient } & \multirow[b]{2}{*}{$\begin{array}{c}\text { IF } \\
\text { Etiology }\end{array}$} & \multirow[b]{2}{*}{$\begin{array}{l}\text { Age, } \\
y\end{array}$} & \multicolumn{6}{|c|}{ PN } & \multicolumn{2}{|c|}{ Liver Total PSs } & \multicolumn{2}{|c|}{ Histologic } \\
\hline & & & $\begin{array}{c}\text { Energy, } \\
\%\end{array}$ & $\begin{array}{c}\text { Lipid } \\
\text { Emulsion }\end{array}$ & $\begin{array}{c}\text { Duration, } \\
\text { mo }\end{array}$ & $\begin{array}{c}\text { Lipid } \\
\text { Calories, } \\
\%\end{array}$ & $\begin{array}{l}\text { Lipid, } \\
\mathrm{g} / \mathrm{kg} / \mathrm{d}\end{array}$ & $\begin{array}{c}\text { Plant } \\
\text { Sterols, } \\
\mu \mathrm{g} / \mathrm{kg} / \mathrm{d}\end{array}$ & $\begin{array}{l}\mu \mathrm{g} / 100 \mathrm{~g} \\
\text { of Liver }\end{array}$ & $\begin{array}{c}100 \times \mu \mathrm{g} / \\
\text { mg of } \\
\text { Cholesterol }\end{array}$ & $\begin{array}{c}\text { Portal } \\
\text { Inflammation }\end{array}$ & Fibrosis \\
\hline 1 & CIPO & 5.53 & 90 & Clinoleic & 11 & 21 & 3.5 & 4841 & 7130 & 1996 & No & No \\
\hline 2 & SBS & 18.6 & 45 & Clinoleic & 1.6 & $-^{\mathrm{a}}$ & $-^{\mathrm{a}}$ & $\underline{-}^{\mathrm{a}}$ & 19,130 & 3816 & Yes & Yes \\
\hline 3 & SBS & 1.74 & 50 & Clinoleic & 21 & 29 & 1.5 & 2014 & 14,040 & 4420 & Yes & Yes \\
\hline 4 & SBS & 0.20 & 100 & Clinoleic & 0.7 & 15 & 1.7 & 2287 & 49,530 & 4036 & Yes & Yes \\
\hline 5 & SBS & 5.58 & 20 & Clinoleic & 61 & 13 & 0.47 & 1031 & 3920 & 1762 & No & Yes \\
\hline 6 & SBS & 0.76 & 17 & SMOF & 9.3 & 11 & 0.40 & 413 & 4700 & 1285 & Yes & Yes \\
\hline 7 & SBS & 0.90 & 75 & $\begin{array}{l}\text { Clinoleic }+ \\
\text { Omegaven }\end{array}$ & 11 & 13 & 0.79 & 464 & 5160 & 1137 & No & No \\
\hline
\end{tabular}

CIPO, chronic intestinal pseudo obstruction; IF, intestinal failure; PN, parenteral nutrition; PS, plant sterol; SBS, short bowel syndrome; SMOF, soy, olive, fish oil, and medium-chained triglycerides.

${ }^{a}$ Detailed parenteral lipid dosage was not available for 1 patient.

may advocate hepatic inflammation by downregulating FXR and by activating liver macrophages. ${ }^{4}$ Accordingly, all liver PS fractions were increased in patients with PI, which is a common early histopathologic finding in IFALD ${ }^{30,33}$ and associates with cholestasis ${ }^{5}$ as well as with elevated serum stigmasterol and avenasterol ratios in IF children. ${ }^{12}$ We found PI to associate more strongly with liver than serum PS levels, suggesting that the underlying cause would be the hepatic accumulation of PS rather than PN administration as such.

Another important mechanism in the pathogenesis of IFALD is proinflammatory signaling through permeable bowel wall, which likely promotes hepatic inflammation. ${ }^{4,9}$ Indeed, stigmasterol induced hepatocyte injury and inflammation in mice only when intestinal integrity was disrupted. ${ }^{34}$ Moreover, SBS children are known to be more prone to IFALD than dysmotility patients. ${ }^{35}$ Also, in our study, the child with chronic intestinal pseudo-obstruction and nearly an entire small intestine remaining had no histologic liver injury, despite receiving higher doses of parenteral lipid and PSs than any patient with SBS. Once an inflammatory state has been established, the increased cytokine signaling may further suppress FXR expression and exacerbate hepatocyte damage, suggesting that the development of inflammation may be crucial in IFALD progression. ${ }^{4,34}$ These data are also in line with our finding that liver fibrosis occurred during PN almost exclusively in the presence of PI.

The small sample size, use of olive oil-based and fish oilbased PN emulsions instead of pure soy oil, and relatively wellpreserved liver function of the study patients may partly explain the lacking correlations between PS levels and some markers of liver function and cholestasis, including transaminases and bilirubin. Furthermore, serum and liver PSs were measured cross sectionally, and no entire PN history was available for all patients. Despite these limitations, this is the first study demonstrating that in patients with IF, liver PS levels increase during parenteral delivery of vegetable oil-based lipid emulsions and relate with biochemical and histologic liver damage. Although our results do not confirm a causal relationship between liver PS accumulation and IFALD nor rule out other PN components contributing to liver injury, they support the increasingly favored concept proposing that PSs play a key role in the development of IFALD.

In conclusion, significantly higher liver and serum PS levels were found in children with IF who were noncholestatic during PN than after weaning off PN. Liver PS levels were related with parenteral lipid and PS administration and correlated strongly with serum PS concentration. Elevated liver PS levels associated with GT and histologic PI, as well as with liver fibrosis in PN-dependent patients. In addition to future in vitro works unraveling further molecular mechanisms behind IFALD, more clinical studies are warranted to increase our knowledge on the metabolic effects and distribution of PSs, as well as safe PN administration in patients with IF.

\section{Statement of Authorship}

M. P. Pakarinen is responsible for the study design and contributed to data collection, analyses, and interpretation. M. Hukkinen conducted the analyses, wrote the manuscript, and contributed to study design. A. Mutanen participated in data collection. M. Nissinen, H. Gylling, and L. Merras-Salmio contributed to study design. All authors critically revised the manuscript, accepted the final version, and agree to be accountable for all aspects of work ensuring integrity and accuracy.

\section{References}

1. Lauriti G, Zani A, Aufieri R, et al. Incidence, prevention, and treatment of parenteral nutrition-associated cholestasis and intestinal failure-associated liver disease in infants and children: a systematic review. JPEN J Parenter Enteral Nutr. 2014;38:70-85.

2. Kelly DA. Preventing parenteral nutrition liver disease. Early Hum Dev. 2010;86:683-687. 
3. D'Antiga L, Goulet O. Intestinal failure in children: the European view. J Pediatr Gastroenterol Nutr. 2013;56:118-126.

4. El Kasmi KC, Anderson AL, Devereaux MW, et al. Phytosterols promote liver injury and Kupffer cell activation in parenteral nutrition-associated liver disease. Sci Transl Med. 2013;5:206ra137.

5. Mutanen A, Lohi J, Heikkila P, Koivusalo AI, Rintala RJ, Pakarinen MP. Persistent abnormal liver fibrosis after weaning off parenteral nutrition in pediatric intestinal failure. Hepatology. 2013;58:729-738.

6. Llop JM, Virgili N, Moreno-Villares JM, et al. Phytosterolemia in parenteral nutrition patients: implications for liver disease development. Nutrition. 2008;24:1145-1152.

7. Clayton PT, Whitfield P, Iyer K. The role of phytosterols in the pathogenesis of liver complications of pediatric parenteral nutrition. Nutrition. 1998;14:158-164.

8. Kurvinen A, Nissinen MJ, Andersson S, et al. Parenteral plant sterols and intestinal failure-associated liver disease in neonates. $J$ Pediatr Gastroenterol Nutr. 2012;54:803-811.

9. Zaloga GP. Phytosterols, lipid administration, and liver disease during parenteral nutrition. JPEN J Parenter Enteral Nutr. 2015;39:39S-60S.

10. Vlaardingerbroek $\mathrm{H}, \mathrm{Ng} \mathrm{K}$, Stoll B, et al. New generation lipid emulsions prevent PNALD in chronic parenterally fed preterm pigs. J Lipid Res. 2014;55:466-477.

11. Sudhop T, Sahin Y, Lindenthal B, et al. Comparison of the hepatic clearances of campesterol, sitosterol, and cholesterol in healthy subjects suggests that efflux transporters controlling intestinal sterol absorption also regulate biliary secretion. Gut. 2002;51:860-863.

12. Mutanen A, Nissinen MJ, Lohi J, Heikkila P, Gylling H, Pakarinen MP. Serum plant sterols, cholestanol, and cholesterol precursors associate with histological liver injury in pediatric onset intestinal failure. Am J Clin Nutr. 2014;100:1085-1094.

13. Savini S, D'Ascenzo R, Biagetti C, et al. The effect of 5 intravenous lipid emulsions on plasma phytosterols in preterm infants receiving parenteral nutrition: a randomized clinical trial. Am J Clin Nutr. 2013;98:312-318.

14. Hallikainen M, Huikko L, Kontra K, et al. Effect of parenteral serum plant sterols on liver enzymes and cholesterol metabolism in a patient with short bowel syndrome. Nutr Clin Pract. 2008;23:429-435.

15. Kurvinen A, Nissinen MJ, Gylling H, et al. Effects of long-term parenteral nutrition on serum lipids, plant sterols, cholesterol metabolism, and liver histology in pediatric intestinal failure. J Pediatr Gastroenterol Nutr. 2011;53:440-446.

16. Park HW, Lee NM, Kim JH, Kim KS, Kim SN. Parenteral fish oilcontaining lipid emulsions may reverse parenteral nutrition-associated cholestasis in neonates: a systematic review and meta-analysis. $J$ Nutr. 2015;145:277-283.

17. Iyer KR, Spitz L, Clayton P. BAPS prize lecture: new insight into mechanisms of parenteral nutrition-associated cholestasis. Role of plant sterols. British Association of Paediatric Surgeons. J Pediatr Surg. 1998;33:1-6.

18. Merras-Salmio L, Pakarinen MP. Refined multidisciplinary protocol based approach to short bowel syndrome improves outcomes. J Pediatr Gastroenterol Nutr. 2015;61(1):24-29.
19. Struijs MC, Diamond IR, de Silva N, Wales PW. Establishing norms for intestinal length in children. J Pediatr Surg. 2009;44:933-938.

20. Hukkinen M, Kivisaari R, Lohi J, et al. Transient elastography and aspartate aminotransferase to platelet ratio predict liver injury in pediatric intestinal failure. Liver Int. 2016;36(3):361-369.

21. Xu Z, Harvey KA, Pavlina T, et al. Steroidal compounds in commercial parenteral lipid emulsions. Nutrients. 2012;4:904-921.

22. Bedossa P, Dargere D, Paradis V. Sampling variability of liver fibrosis in chronic hepatitis C. Hepatology. 2003;38:1449-1457.

23. Miettinen TA. Cholesterol metabolism during ketokonazole treatment in man. J Lipis Res. 1988;29:43-51.

24. Forchielli ML, Bersani G, Tala S, Grossi G, Puggioli C, Masi M. The spectrum of plant and animal sterols in different oil-derived intravenous emulsions. Lipids. 2010;45:63-71.

25. Reimund JM, Arondel Y, Joly F, Messing B, Duclos B, Baumann R. Potential usefulness of olive oil-based lipid emulsions in selected situations of home parenteral nutrition-associated liver disease. Clin Nutr. 2004;23:1418-1425.

26. Burrin DG, Ng K, Stoll B, Saenz De Pipaon M. Impact of new-generation lipid emulsions on cellular mechanisms of parenteral nutrition-associated liver disease. Adv Nutr. 2014;5:82-91.

27. Skouroliakou M, Konstantinou D, Agakidis C, et al. Cholestasis, bronchopulmonary dysplasia, and lipid profile in preterm infants receiving MCT/ omega-3-PUFA-containing or soybean-based lipid emulsions. Nutr Clin Pract. 2012;27:817-824

28. Pakarinen MP, Kurvinen A, Gylling H, et al. Cholesterol metabolism in pediatric short bowel syndrome after weaning off parenteral nutrition. Dig Liver Dis. 2010;42:554-559.

29. Pianese P, Salvia G, Campanozzi A, et al. Sterol profiling in red blood cell membranes and plasma of newborns receiving total parenteral nutrition. J Pediatr Gastroenterol Nutr. 2008;47:645-651.

30. Naini BV, Lassman CR. Total parenteral nutrition therapy and liver injury: a histopathologic study with clinical correlation. Hum Pathol. 2012;43:826-833.

31. Carter BA, Taylor OA, Prendergast DR, et al. Stigmasterol, a soy lipidderived phytosterol, is an antagonist of the bile acid nuclear receptor FXR. Pediatr Res. 2007;62:301-306.

32. Mandal S, Miraglia R, Maruzzelli L, et al. US-guided percutaneous liver biopsy in pediatric liver transplant recipients. J Pediatr Gastroenterol Nutr. 2014;58:756-761.

33. Buchman AL, Iyer K, Fryer J. Parenteral nutrition-associated liver disease and the role for isolated intestine and intestine/liver transplantation. Hepatology. 2006;43:9-19.

34. El Kasmi KC, Anderson AL, Devereaux MW, et al. Toll-like receptor 4-dependent Kupffer cell activation and liver injury in a novel mouse model of parenteral nutrition and intestinal injury. Hepatology. 2012;55:1518-1528.

35. Pakarinen MP, Koivusalo AI, Rintala RJ. Outcomes of intestinal failure: a comparison between children with short bowel and dysmotile intestine. J Pediatr Surg. 2009;44:2139-2144. 